\title{
Could Cardiovascular Parameters Be Affected by Dental Impression?
}

\author{
Fatemeh Owlia ${ }^{1}$, Mohammad Hassan Akhavan Karbassi ${ }^{1}$, Roqayeh Hakimian ${ }^{1}$ and Elahe Zakerinia ${ }^{2,{ }^{*}}$ \\ ${ }^{1}$ Yazd Shahid Sadoughi University of Medical Science, Yazd, Iran \\ ${ }^{2}$ Private Practice, Yazd, Iran \\ "Corresponding author: Private Practice, Daha Fajr Blvd., Yazd, Iran. Tel: +98-9132733775, Email: dents1390@gmail.com
}

Received 2018 November 04; Revised 2019 January 04; Accepted 2019 January 11.

\begin{abstract}
Background: The frequency of cardiovascular disease increases with age. Dental procedures as stressful triggers may cause unpredictable changes in the function of the cardiovascular system. Impression is an inevitable dental procedure.

objectives: Since upper jaw impression stimulates the sensory terminals of nerves, especially vagus, this study was conducted to evaluate the changes in blood pressure, heart rate, and pulse pressure due to dental impression.

Methods: This observational study was performed on individuals who referred to the Prosthetic Department of Yazd Dental School. The sample was composed of 46 individuals, including 26 women and 20 men, who fulfilled the inclusion criteria and signed written consent forms. The severity of gag reflex was measured and just individuals with moderate gag reflex entered the study. Impression was carried out in the upper jaw in the upright position and rest condition. Blood pressure, pulse rate, and pulse pressure were measured and compared before and immediately after impression procedure. Taking into account the significance level of $5 \%$, the test power of $80 \%$, and blood pressure standard deviation of 4 , and to achieve a significant difference of at least $2 \mathrm{mmHg}$ in the groups, 46 people were needed in the study. Data were analyzed by SPSS 18 and $t$ test.

Results: Systolic and diastolic blood pressure, heart rate, and pulse pressure were measured before and after dental impression. The difference between men and women was significant only for pulse pressure at both stages $(\mathrm{P}=0.02)$. There was also a statistically significant difference in pulse pressure before and after impression only in women $(\mathrm{P}=0.049)$. There was no significant difference in men.
\end{abstract}

Conclusions: Common dental procedures such as impression could not significantly alter blood pressure and pulse rate.

Keywords: Blood Pressure, Denture, Heart Rate

\section{Background}

There are many defensive reflexes such as coughing, swallowing, and gag in the throat and larynx that originate from the mouth (1). The gag reflex is an unintentional and protective reaction to prevent the entrance of external materials into the oropharynx. Stimulation of the throat can act as a trigger to increase blood pressure and heart rate because of nerves passing through the palate.

Most dental procedures, such as impression, can stimulate a gag reflex $(1,2)$. During the impression of the upper jaw, the branches of nerves 5, 9, and 10 are stimulated. During the stimulation of this region, the afferent fibers go to the medulla oblongata. Then, impulses of the efferent nerve are taken to muscles, leading to a gag reflex. The gag reflex due to parasympathetic stimulation can lead to salivation, tearing, sweating, weakness or in some cases, panic attacks (3). Faraco et al. showed a significant difference in diastolic blood pressure between three groups that took diazepam, placebo, or no medication (4).
The gag reflex is divided into somatogenic and psychogenic categories. The psychogenic reflex begins with anxiety, fear, and panic while the somatogenic reflex is triggered by physical factors such as poor denture stability, inaccurate vertical dimension, malocclusion, loss of enough space for the tongue, and the thick posterior margin of the denture (5). The etiology of the reflex includes congenital anomalies, alcoholism, biliary tract obstruction, and drugs. Some chemical, auditory, visual, physical, and stimulatory factors including psychological, physiological, anatomical, iatrogenic, and systemic factors could act as triggers. The gag reflex has a wide range of severity from normal to very severe (5). Different strategies are suggested to overcome this reflex such as anesthetic drugs and intravenous propofol $(1,6)$.

It is worthy to mention that the incidence of cardiovascular disease in people over 50 is high and it may be associated with indolent symptoms (7). The ignorance of these points may lead to cerebral hemorrhage, heart at- 
tack, stroke, heart failure, arterial aneurysm, arteriosclerosis, and pulmonary embolism (8).

\section{Objectives}

The occurrence of such events in dental offices may involve dentists with legal challenges because of failure to observe necessary considerations before or during treatment. Therefore, this study was designed to investigate some cardiac indices before and after the maxillary impression.

\section{Methods}

This observational study was performed by census sampling from September to December 2016 at Yazd Dental School among 46 patients referring to the Prosthetic Department. The sample was composed of 26 women and 20 men who met the inclusion criteria including the age of over 50 years, no systemic problems prohibiting jaw molding, use of no drugs affecting the sympathetic system in the last month, and gag reflex grade $1-3$. This study was approved by the Ethics Committee of Yazd Shahid Sadoughi University of Medical Sciences (IR.ssu.REC.1395.116) and written informed consent was taken from all participants. In this study, taking into account the significance level of $5 \%$, the test power of $80 \%$, and the blood pressure standard deviation of 4 , and to achieve a significant difference of at least $2 \mathrm{mmHg}$ in the groups, 32 individuals were needed.

First, the grade of gag reflex was evaluated in all participants according to Table 1 and only were individuals with grades 1 to 3 enrolled and people with grades 4 or 5 did not enter the study. The maxillary impression was performed using a metal stock tray and irreversible hydrocolloid impression material (alginate manufactured by Zhermack, China). To eliminate the possible impact of physical activities on blood pressure and pulse rate, the participants rested for at least 15 minutes to calm before the dental impression.

The impression was done in 60 to 90 seconds between 9:00 and 11:00 a.m. in the same condition in quiet condition with proper light. Blood pressure was measured at two stages, before and immediately after impression, by the ALPK2 digital arm metric barometric blood pressure device while the patient was on the unit. The device had been calibrated with the mercury brachial barometric arm before the start of the evaluation. The duration of impression procedure was measured with konometer (Kenko, China) from the moment of insertion of the tray into the mouth until it was exited. Data were entered into SPSS18 software and analyzed by $t$ test.

\begin{tabular}{ll}
\hline Table 1. Definition of Each GSI Grade and Characteristics of Reflex Grades (9) \\
\hline $\begin{array}{l}\text { Dickinson and Fiske } \\
\text { Gagging Severity Index } \\
\text { Grades }\end{array}$ & $\begin{array}{l}\text { Definition and Characteristics of Reflex } \\
\text { Grades }\end{array}$ \\
\hline Grade I & $\begin{array}{l}\text { Very mild, occasional and controlled by the } \\
\text { patient }\end{array}$ \\
\hline Grade II & $\begin{array}{l}\text { Moderate, control is required by the patient } \\
\text { with reassurance from the dental team }\end{array}$ \\
\hline Grade III & $\begin{array}{l}\text { Moderate, consistent, limiting treatment } \\
\text { options }\end{array}$ \\
Grade IV & $\begin{array}{l}\text { Severe, making treatment impossible } \\
\text { Grade V }\end{array}$ \\
\hline
\end{tabular}

\section{Results}

Dental impression made no significant difference in systolic blood pressure and pulse pressure $(\mathrm{P}=0.07)$, heart rate $(\mathrm{P}=0.079)$, and diastolic blood pressure $(\mathrm{P}=0.229)$ (

\begin{tabular}{lccc}
\hline $\begin{array}{l}\text { Table 2. The Mean Cardiovascular Parameters Before and After Dental Impression } \\
\text { Variables }\end{array}$ & \multicolumn{2}{c}{ Impression } & P Value \\
\cline { 2 - 3 } & $\begin{array}{c}\text { Before, Mean } \\
\pm \text { SD }\end{array}$ & $\begin{array}{c}\text { After, Mean } \pm \\
\text { SD }\end{array}$ & \\
\hline $\begin{array}{l}\text { Systolic } \\
\text { pressure }\end{array}$ & $123.17 \pm 16.93$ & $122.78 \pm 13.96$ & 0.7 \\
$\begin{array}{l}\text { Diastolic } \\
\text { pressure }\end{array}$ & $73.35 \pm 10.85$ & $72.54 \pm 9.65$ & 0.229 \\
\hline $\begin{array}{l}\text { Heart rate } \\
\text { Pulse pressure }\end{array}$ & $80 \pm 12.72$ & $81.04 \pm 12.18$ & 0.079 \\
\hline a $t$ test & $49.83 \pm 8.6$ & $51.59 \pm 8.78$ & 0.07 \\
\hline
\end{tabular}

There was no significant difference before impression between men and women in systolic blood pressure ( $\mathrm{P}=$ $0.219)$, diastolic blood pressure $(\mathrm{P}=0.935)$, and heart rate $(\mathrm{P}=0.945)$. However, there was a significant difference between men and women in pulse pressure $(P$ value $=0.02)$ before impression.

Moreover, there was no significant difference between men and women after impression in systolic blood pressure $(P=0.308)$, diastolic blood pressure $(P=0.691)$, and heart rate $(P=0.926)$ but there was a significant difference in pulse pressure between men and women $(\mathrm{P}=0.028)$ after impression.

Before dental impression, men and women showed the mean systolic blood pressure of 120.46 and 126.7, diastolic blood pressure of 73.23 and 73.5 , heart rate of 80.12 and 79.85 , and pulse pressure of 47.23 and 53.20, respectively.

After dental impression, men and women showed the mean systolic blood pressure of 120.92 and 125.2, diastolic blood pressure of 72.04 and 73.2, heart rate of 81.19 and 
80.85, and pulse pressure of 48.88 and 55.10, respectively (Table 3).

In the women group, no statistically significant difference was found in systolic blood pressure before and after dental impression; however, the difference in diastolic blood pressure and heart rate was statistically significant $(\mathrm{P}=0.04)$

\section{Discussion}

This study was performed on 46 patients who required complete denture, referring to the Prosthetic Department of Yazd Dental School.

This study was superior in terms of the sample size to some studies and inferior to others $(10,11)$. It is worthy to note that having rigorous inclusion criteria leads to limited sample size $(12,13)$. In this study, all individuals would be over 50 years of age with no known systemic diseases. On the other hand, they would not have taken any drug with side effects on sympathetic and parasympathetic systems in the past month.

All of the participants were aged over 50 years. Thus, our study was superior to other studies that did not have any restrictions on age. Some goals were achieved with this selection design.

One of the main advantages of this study was to rule out isolated diastolic hypertension that is common at the age of under 50 years and it could affect the result of the study. Thus, the age group was selected over 50 years old to omit this bias from the study.

On the other hand, in women under 50 years, sexual hormones can significantly affect the vascular system. Therefore, selecting a group of people over 50 was important. The risk of cardiovascular diseases increases with age while the need of the elderly for dental care is on the rise. The risk of cardiovascular events increases during dental work that is a challenging debate in forensic medicine.

The results of this study showed that following common dental practices, even if a direct parasympathetic stimulation occurs (as in the case of maxillary impression and posterior palatal stimulation in this study), changes in the cardiovascular system are not statistically significant and the notion was questioned that conventional dentistry treatments in the elderly can cause decreased blood pressure and arrhythmia. These results were inconsistent with those of Paramaesvaran and Kingon that concluded exodontia could significantly decrease the pulse rate in contrast to blood pressure (14).

Past studies evaluated some of cardiovascular parameters that we measured here (15).

In some studies, such as Piskin et al. study, oxygen saturation and pulse rate were evaluated at different stages of the study but considering that oxygen saturation is not merely an indicator of the cardiovascular system and changes in the respiratory system are common in the elderly, this variable is strongly influenced by respiratory problems. Therefore, complex medical equipment is required that is not normally found in a dental office. Thus, this study was designed to evaluate parasympathetic effects on the cardiovascular system by measuring available indicators (15). Some studies have concluded that usual dental procedures could not induce significant changes in blood pressure whereas some others have reported that local anesthesia can lead to elevated blood pressure. Therefore, there are controversies about the issue (16). It should be considered that some procedures such as extraction and injection may induce more stress because of the vasoconstrictor material in local anesthesia (17).

In terms of outcome, the study was consistent with the study by Piskin et al. that reported a significant difference in pulse pressure at two stages of the study. It should be noted that the current study investigated the two aspects of this problem. When blood pressure, pulse rate, and pulse pressure were analyzed without sex separation, the difference was not significant before and after dental impression (15). But, when the sex groups were separately analyzed, it was found that unlike other variables, pulse pressure difference was statistically significant before and after dental impression in women.

This dual conclusion suggests that the coordination of the cardiovascular system in women was higher due to the presence of female hormones and its impact was greater than the external stimulus, making this significant difference. However, there are some studies concluding that usual dental procedures could not induce significant changes in blood pressure in adults, but others believe that more aggressive dental treatments such as infiltration injection can lead to blood pressure elevation. Therefore, there is currently a big challenge with major controversy.

In this study, the impression was done after 15 minutes in a rest position to eliminate the impact of daily activity. The impression procedure lasted 60 to 90 seconds and it was observed for all participants. Prolonged or repeated cases were excluded from the study to avoid excessive posterior palatal stimulation.

The method of this study was similar to that of Hosseini et al. study that appraised the role of the parasympathetic system on cardiovascular stimulus but they evoked the posterior region of the palate by an electric device at two frequencies (10). For achieving the goal of this study, the use of such device was not acceptable although, in both studies, the stimulation of the parasympathetic system made no significant changes $(10,18,19)$.

Pulse pressure was significantly different between the 


\begin{tabular}{|c|c|c|c|c|}
\hline Impression & Systolic Blood Pressure; Mean \pm SD & Diastolic Blood Pressure; Mean \pm SD & Heart Rate; Mean $\pm S D$ & Pulse Pressure; Mean \pm SD \\
\hline \multicolumn{5}{|l|}{ Before } \\
\hline Men & $120.46 \pm 16.79$ & $73.23 \pm 10.68$ & $80.12 \pm 10.62$ & $47.23 \pm 7.73$ \\
\hline Women & $126.7 \pm 16.89$ & $73.5 \pm 11.34$ & $79.85 \pm 15.31$ & $53.2 \pm 8.86$ \\
\hline Pvalue & 0.219 & 0.935 & 0.945 & 0.02 \\
\hline \multicolumn{5}{|l|}{ After } \\
\hline Men & $120.92 \pm 14.61$ & $72.04 \pm 10.24$ & $81.19 \pm 10.61$ & $48.88 \pm 5.46$ \\
\hline Women & $125.2 \pm 13.02$ & $73.2 \pm 9.04$ & $80.85 \pm 14.25$ & $55.1 \pm 10.96$ \\
\hline Pvalue & 0.308 & 0.691 & 0.926 & 0.028 \\
\hline
\end{tabular}

two sexes at the two stages of the study. Since pulse pressure is the difference between systolic and diastolic blood pressure, its stability indicates the proper functioning of the autonomic and cardiovascular systems. In the fertility period, female hormones could maintain vascular function in optimal condition and provide stability and balance between the two systems. However, after menopause, the cardiac function remains intact while due to the subsidence of female hormones, vascular system function significantly reduces $(20,21)$. Therefore, the coordination of the autonomic system in the new state disrupts or falls into a delay. In comparison, the difference between women and men in the same age over 50 years was significant during the study period.

Superiorities of our work to recent studies can be summarized as follows: evaluating more complete cardiac parameters, having rigorous inclusion criteria, and having a special target group (the edentulous elderly). Among different dental procedures, the maximum stimulation of the gag reflex occurs during maxillary dental impression that was the point of attention in this study while ignored in previous studies $(10,14)$.

It is suggested that similar studies be conducted on prolonged or repeated impression cases to compare with the current study. Choosing people with no systemic disease and drug use who required complete dentures and impression in a calibrated situation restricted the sample selection for the study.

\subsection{Conclusions}

Common dental procedures such as maxillary impression despite the stimulation of the sensory terminals of the posterior palate could not have a significant effect on blood pressure and pulse rate.

\section{Footnotes}

Authors' Contribution: Study concept and design and critical revision of the manuscript for important intellectual content: Fatemeh Owlia and Mohammad Hassan Akhavan Karbassi; acquisition of data: Elahe Zakerinia; analysis and interpretation of data, drafting of the manuscript, and statistical analysis: Fatemeh Owlia and Mohammad Hassan Akhavan Karbassi; administrative, technical, material support and study supervision: Fatemeh Owlia and Roqayeh Hakimian.

Conflict of Interests: There are no conflicts of interest.

Ethical Approval: The study protocol was reviewed and confirmed by the Medical Ethics Committee of Yazd Shahid Sadoughi University of Medical Sciences, Yazd, Iran (IR.ssu.REC.1395.116).

Funding/Support: Research Deputy of Yazd Shahid Sadoughi University of Medical Science supported this study as the doctors thesis.

Patient Consent: Written ethical consent was taken from all participants.

\section{References}

1. Haghani J, Naser Khaki M. The study of effection of salt (Nacl) on temporary elimination of gag reflex. J Dent Sch. 2003;21(1):31-5.

2. Kumar S, Satheesh P, Savadi RC. Gagging. NYState Dent J. 2011;77(4):227. [PubMed: 21894827].

3. Bassi GS, Humphris GM, Longman LP. The etiology and management of gagging: A review of the literature.J Prosthet Dent. 2004;91(5):45967. doi: 10.1016/S0022391304000939. [PubMed: 15153854].

4. Faraco FN, Armonia PL, Simone JL, Tortamano N. Assessment of cardiovascular parameters during dental procedures under the effect of benzodiazepines: A double blind study. Braz Dent J. 2003;14(3):215-9. [PubMed: 15057400].

5. Singh S, Ali FM, Nazirkar G, Dole VK, Gaikwad B. Gag- etiology and its skillfull management- a review. J Evol Med Dent Sci. 2013;2(10):1509-16. doi: $10.14260 /$ jemds/416. 
6. Hekmatian E, Shadmehr E, Asghari G. Effect of Elaeagnus Angustifolia lozenge on gag reflex in dental patients. J Islam Dent Assoc Iran. 2012;24(2):2

7. Nikinoosheri R. Blood pressure and pulse changes in periodontal patients referring to Ghazi Tabatabai Clinic in Tehran in the summer and autumn of 2003 [dissertation]. Faculty of Dentistry, Shahid Beheshti University of Medical Sciences; 2004.

8. Greenberg MS, Glick M, Ship JA. Burket's oral medicine: Diagnosis and treatment. Hamilton: BC Decker; 2014.

9. Hearing CM, Bind RH, Tabacco MJ, Hallock RM. A Reliable and Valid Survey to Predict a Patient's Gagging Intensity. J Oral Maxillofac Res. 2014;5(2). e3. doi: 10.5037/jomr.20014.5203. [PubMed: 25089175]. [PubMed Central: PMC4115595].

10. Hosseini SM, Jamshir M, Maleki A. The effect of gag reflex on cardiac sympatovagal tone. Oman Med J. 2012;27(3):249-50. doi: 10.5001/omj.2012.57. [PubMed: 22811779]. [PubMed Central: PMC3394352].

11. Yoshida H, Ayuse T, Ishizaka S, Ishitobi S, Nogami T, Oi K. Management of exaggerated gag reflex using intravenous sedation in prosthodontic treatment. Tohoku J Exp Med. 2007;212(4):373-8. [PubMed: 17660702]

12. Abraham-Inpijn L, Borgmeijer-Hoelen A, Gortzak RA. Changes in blood pressure, heart rate, and electrocardiogram during dental treatment with use of local anesthesia. J Am Dent Assoc. 1988;116(4):531-6. doi: 10.14219/jada.archive.1988.0318. [PubMed 3164019].

13. Uesugi N, Ono Y, Iwayama K, Asai T, Tanaka E, Komasa Y. Blood pressure fluctuation during impression taking: Relationship between blood pressure and temperature of water used for mixing the impression material. J Osaka Dent Univ. 2006;40(2):93-7.

14. Paramaesvaran M, Kingon AM. Alterations in blood pressure and pulse rate in exodontia patients. Aust Dent J. 1994;39(5):282-6.
[PubMed: 7811204].

15. Piskin B, Karakoc O, Emir F, Uyar A, Sipahi C, Tasci C, et al. Can impression procedures affect certain vital functions of edentulous patients? A clinical study.JProsthodont. 2016;25(3):196-201. doi:10.1111/jopr.12392. [PubMed: 26502182].

16. Chobanian AV, Bakris GL, Black HR, Cushman WC, Green LA, Izzo JJ, et al. The seventh report of the Joint National Committee on Prevention, Detection, Evaluation, and Treatment of High Blood Pressure: The JNC 7 report. JAMA. 2003;289(19):2560-72. doi: 10.1001/jama.289.19.2560. [PubMed: 12748199].

17. Southerland JH, Gill DG, Gangula PR, Halpern LR, Cardona CY, Mouton CP. Dental management in patients with hypertension: Challenges and solutions. Clin Cosmet Investig Dent. 2016;8:111-20. doi: 10.2147/CCIDE.S99446. [PubMed: 27799823]. [PubMed Central: PMC5074706].

18. Sakamoto T, Fukuda K, Saita N, Koukita Y, Yamashita S, Koizumi J, et al. Autonomic nervous activity of patients with gagging problems during dental mirror insertion. Spec Care Dentist. 2016;36(2):80-4. doi: 10.1111/scd.12148. [PubMed: 26681625].

19. Sun J, Scherlag BJ, He BO, Shen X, Gao M, Zhang L, et al. Electrical stimulation of vascular autonomic nerves: Effects on heart rate, blood pressure, and arrhythmias. Pacing Clin Electrophysiol. 2015;38(7):82530. doi: 10.1111/pace.12603. [PubMed: 25640056].

20. Machi JF, Dias Dda S, Freitas SC, de Moraes OA, da Silva MB, Cruz PL, et al. Impact of aging on cardiac function in a female rat model of menopause: Role of autonomic control, inflammation, and oxidative stress. Clin Interv Aging. 2016;11:341-50. doi: 10.2147/CIA.S88441. [PubMed: 27042032]. [PubMed Central: PMC4809309].

21. Gordan R, Gwathmey JK, Xie LH. Autonomic and endocrine control of cardiovascular function. World J Cardiol. 2015;7(4):204-14. doi: 10.4330/wjc.v7.i4.204. [PubMed: 25914789]. [PubMed Central: PMC4404375]. 